\title{
Archetype, adaptation and the mammalian heart
}

\author{
F. L. Meijler • T. D. Meijler
}

Published online: 22 February 2011

(C) The Author(s) 2011. This article is published with open access at Springerlink.com

\begin{abstract}
Forty years ago, we started our quest for 'The Holy Grail' of understanding ventricular rate control and rhythm in atrial fibrillation (AF). We therefore studied the morphology and function of a wide range of mammalian hearts. From mouse to whale, we found that all hearts show similar structural and functional characteristics. This suggests that the mammalian heart remained well conserved during evolution and in this aspect it differs from other organs and parts of the mammalian body. The archetype of the mammalian heart was apparently so successful that adaptation by natural selection (evolution) caused by varying habitat demands, as occurred in other organs and many other aspects of mammalian anatomy, bypassed the heart. The structure and function of the heart of placental mammals have thus been strikingly conserved throughout evolution. The changes in the mammalian heart that did take place were mostly adjustments (scaling), to compensate for variations in body size and shape. A remarkable scaling effect is, for instance, the difference in atrioventricular (AV) conduction time, which is vital for optimal cardiac function in all mammals, small and large. Scaling of AV conduction takes place in the $\mathrm{AV}$ node (AVN), but its substrate is unknown. This sheds new light on the vital role of the AVN in health and disease. The AVN is master and servant of the
\end{abstract}

${ }^{\dagger}$ F. L. Meijler died on December 28, 2010. Correspondence should be addressed to E. E. van der Wall.

F. L. Meijler ${ }^{\dagger}$

Utrecht University and Interuniversity Cardiology Institute,

Utrecht, the Netherlands

e-mail: e.e.van_der_wall@lumc.nl

T. D. Meijler

SAP Research CEC,

Chemnitzer Strasse 48,

Dresden, Germany heart at the same time and is of salient importance for our understanding of supraventricular arrhythmias in humans, especially AF. In Information Technology a software infrastructure called 'enterprise service bus' (ESB) may provide understanding of the mammalian heart's conservation during evolution. The ESB is quite unspecific (and thus general) when compared with the specialised components it has to support. For instance, one of the functions of an ESB is the routing of messages between system nodes. This routing is independent and unaware of the content of the messages. The function of the heart is likewise independent and unaware of the routing of blood (oxygen) and of the specialised components of the mammalian body it has to support. Conclusions Evolution seems to have bypassed the heart, which is in contrast to the sometimes similarly looking, but yet quite differently functioning of the other organs of the mammalian body.

Keywords Archetype - Adaptation - Natural selection . Evolution $\cdot$ AV node \& conduction $\cdot$ Scaling $\cdot$ Mammalian hearts

\section{Rationale of the Study}

In 1970 we published a study on the random ventricular rhythm in patients with atrial fibrillation (AF) [1]. Since then the number of publications of studies of the electrophysiology, clinical importance and social relevance of AF has exploded. Although an abundant amount of information on the cause and treatment of $\mathrm{AF}$ has become available, knowledge of its electrophysiology and of the role of the atria and the atrioventricular node (AVN) in ventricular rate control is still insufficient to understand all aspects of AF $[2,3]$. Clinically, it is customary to accept the notion of one type of AF but from a more fundamental point of view 
different causes and different forms may be more realistic and could result in more efficient forms of treatment [4]. In one of his landmark papers on this subject, Gordon Moe has explained why 'small' hearts seldom fibrillate and showed how AF can sustain itself [5, 6]. Assuming that the cause(s) of AF and the 'Holy Grail' of ventricular rate and rhythm control may be part of heart size and AVN function, we decided to start a comparative study of hearts of differently sized mammalian species $[7,8]$.

\section{Mammalian Heart Conserved Throughout Evolution}

During the many years of study of form and function of mammalian hearts from mouse to whale we found no fundamental differences between the hearts and circulation of otherwise widely dissimilar species [9]. It became apparent that the heart, when compared with most other organs or parts of the mammalian body, has been rather insensitive to the effect of evolution. This conservation of the heart's anatomical appearance and also of its functional performance is remarkable when compared with the notable diversity in body size and shape of mammalian species. It would be useful to present an index of conservation of organs per mammalian species, because each organ has its own morphological and functional parameters. But how to compare the comparison between diastolic and systolic pressures in the four chambers of the hearts of all mammals, with for instance the composition of urine of camels living in the desert versus that of dolphins living in the ocean? With the exception of the heart, all other organs as well as all senses in the bodies of mammalian species seem to display often strong dissimilarity in function.

What could be the reason for the mammalian heart to remain so well conserved during evolution while most other organs in mammals (and maybe in other classes as well) show dramatic changes? Evidently, the archetype of the mammalian heart has been so successful that its original design could not be improved upon [10].

Although impossible to prove, it is almost certain that the contemporary mammalian species inherited their hearts from our common ancestors, the placental mammals, of which the first originated in the Mesozoic, around 125 million years ago. The currently living mammals date back to the end of Cretaceous and beginning of Cenozoic, 65 million years ago $[11,12]$.

Charles Darwin called evolution 'descent with modification' or adaptation by natural selection; 'a more technical, modern definition of evolution is a change in the genetic composition of a population over time' [13, 14]. Evolution shaped all forms of life to warrant survival during the (ever) ongoing changes in local physical conditions on earth such as climate and geology or in the community of organisms that a given species interacts with. In mammals (and not only in mammals) this has resulted in a spectacular diversity of ecomorphological specialisation, apparently with the exception of the heart.

Small changes, yes, and functional adjustment to varying body sizes (scaling aspects) or shape of course, but an amazing overall similarity between the hearts of all mammals seems to be the rule. We may even suggest that: 'The heart does not know in what mammal it functions'.

\section{Morphological Similarity of the Mammalian Heart}

The blueprint for the construction (architecture) of the mammalian heart presents itself as durable and universal, resulting in the heart's similar basic form in all mammals. The book: 'Biology of the Mammal' presents a rabbit heart as the mammalian heart but any mammalian heart would have done [15]. Moreover, with the exception of mitochondrial density which depends on heart size, all cardiac myocytes have the same size and morphology, making it difficult to distinguish the myocytes of one species from another [1619]. The same is true for specialised cardiac tissue such as the His bundles responsible for the conduction of the electrical impulse from the atria to the ventricles [20, 21].

However, being similar is not the same as being identical. There are differences in size of course, and limited differences in the shape of the heart, all depending on the size and shape of the mammal and its habitat. For instance, the whale's heart has the shape of a cube with rounded corners while the human heart is slightly pointed and to a small degree concave posteriorly, due to resting on the diaphragm as a consequence of our orthograde posture [22]. There are also subtle differences among mammals in the shape of the atrial appendages and the extent of trabeculation of the apical components of the ventricles as well minor differences in their conduction system [23, 24].

Rowlatt concluded after an extensive study of comparative anatomy of the hearts of mammals, thereby focusing on differences rather than on similarities, that: 'the heart is indeed a conservative organ retaining ancestral features but its basic construction can be changed if functional selective pressures are great or pleiotropic influences are strong' [24].

There is no clear conservation on the molecular level; for instance, there are genetically linked immune system differences, among others demonstrated by the rejection of tissues and organs during xenotransplantation [25]. Without an immune system one could exchange similar sized hearts, for instance, of a polar bear with that of a camel. Porcine hearts are already being studied to overcome those immunological problems in humans: a promising future solution for heart failure [26]. 
Also myosin differences in the myocardium of small versus large mammals can be found, responsible for the rate of force generation during each atrial and ventricular contraction [27]. However, on the macro and micro (electron) level atria, ventricles, myocardium, conduction system, valves and the coronary system of the heart are for all practical purposes the same in all mammals. Overall similarities of cardiac morphology outweigh the differences among mammalian species.

\section{Functional Similarity of the Mammalian Heart}

Mammalian species live and survive in widely differing habitats, for example polar bears on the North Pole ice and camels in the desert. Despite varying demands on the circulation under those circumstances, their hearts are similar and show identical or nearly identical electrical and mechanical (haemodynamic) behaviour.

\section{The Electrical Function of the Mammalian Heart}

All contractions of atria and ventricles are preceded by their electrical activation. These activations (P and QRS) are linked by a varying time interval. This interval variation depends on heart mass or body mass and controls the optimisation of cardiac output under all circumstances.

Figure 1 shows a schematic representation of the electrical activation and the conduction pathways of the human (mammalian) heart [28]. The PR or PQ interval, AV delay or conduction time consists of three components:

1) Conduction of the electrical impulse through the atrial myocardium from the sinoatrial node $(\mathrm{SN})$ to the atrioventricular node (AVN)

2) Conduction through the AVN proper and

3) Conduction from the AVN through the His bundles, its branches and the Purkinje fibres (HP system) to the ventricular myocardium.

The conduction velocity of the electrical impulse through the HP system is high (in the order of 2-4 m/sec) when compared with the conduction velocity through the atria and the AVN [29]. Although never measured it can be expected that, on the basis of the electrical cable theory, in large mammals (horses, elephants, whales) conduction velocity in the HP system is higher (in any case not lower) than in mammals of smaller dimensions. Nevertheless it will be clear that in small to middle sized hearts (mice to dogs) the HP system, at this high conduction velocity, hardly contributes to the duration of AV delay, while in large hearts the contribution of the HP system to AV delay, depending on its length, can be substantial and is in all probability constant and therefore does not contribute to $\mathrm{AV}$

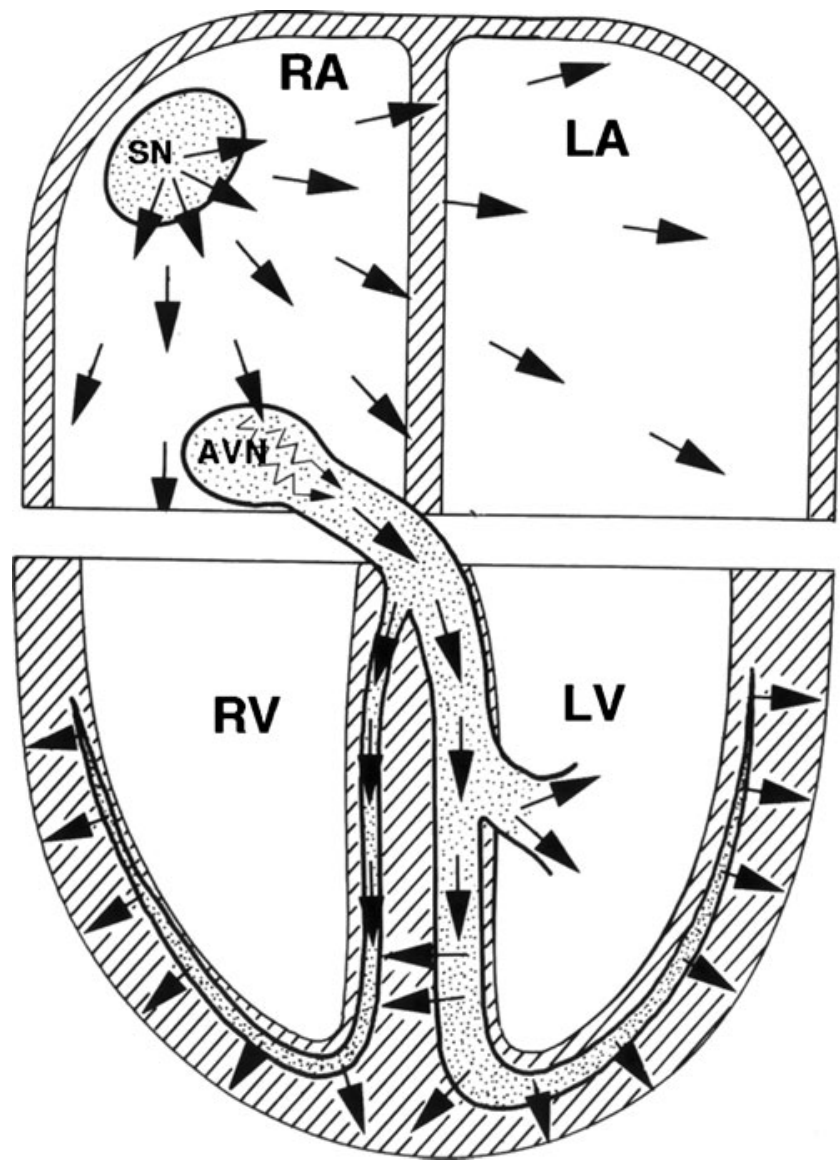

Fig. 1 Schematic and simplified representation of electrical activation and the AV conduction system of the mammalian heart. For further details see text. Art work by Dr A.N.E. Zimmerman, Middelburg, the Netherlands

delay changes. It follows that in all mammals, small and large, the variation in AV delay (PR interval) is caused exclusively by the AVN proper. In fact this delay variation in the AVN is indeed one of the major survival strategies of all mammalian species. In other words the AVN warrants optimal cardiac output according to heart mass and continuous varying heart rates. We can assert that our multifunctional mammalian AVN is master and servant of the heart at the same time [8]. In the context of this paper, the adjustment of AV delay to heart mass (body mass) (scaling) deserves special attention.

\section{Scaling of AV Conduction Time/Delay}

In 1638 Galileo was the first to draw attention to the relationship between body size (mass/weight) ${ }^{1}$ and the dimension of bones in a variety of mammalian species [30].

\footnotetext{
${ }^{1}$ Since the specific gravity of the heart hardly differs from 1 we freely exchange mass, weight, size and volume.
} 
In our time we call this relationship scaling. In biology, 'Scaling deals with the structural and functional consequences of changes in size or scale among otherwise similar organisms'. [31] Scaling in cardiology includes the relation between heart mass (HM) and body mass (BM) $\mathrm{HM}=\mathrm{HM}_{0} \mathrm{BM}^{1}$ [31]. Thus heart mass is proportional to body mass. In all mammals, including humans, heart mass is $0.6 \%$ of body mass [32]. There are also relations between heart mass and stroke volume (SV), $\mathrm{SV}=\mathrm{SV}_{0} \mathrm{HM}^{1}$ and heart rate $\mathrm{HR}=\mathrm{HR}_{0} \mathrm{M}^{0.25}$ so that cardiac output (CO), the product of $\mathrm{HR}$ and $\mathrm{SV}$, is $\mathrm{CO}=\mathrm{CO}_{0} \mathrm{M}^{0.25}$. In contrast blood pressure in the arterial system and diastolic and systolic pressures in the atria and ventricles are the same in all mammals and therefore do not relate to body mass, i.e. their scaling factors are zero $\left(\mathrm{M}^{0}\right)$. Also all mammals, independent of body mass, have the same haemoglobin concentration, and the same oxygen capacity of blood as well as similar sized red cells. [33]

In 1927, Clark was the first to notice the different durations of the PR interval (AV conduction time) in animals of different sizes [34]. Clark asserted that: 'the $P R$ interval on the ECG varies so little in different animals'. We later called this the 'mismatch' between size and function of the heart [9]. The PR intervals in mammals indeed vary, for instance, from about $40 \mathrm{~ms}$ in mice to about $400 \mathrm{~ms}$ in elephants and in the whales we studied $[35,36]$. Figure 2 illustrates the dependence of PR interval on body mass in a number of mammalian species. The PR interval in small mammals is generally longer and in large mammals shorter than expected from the body mass values. The deviation in small mammals (smaller than cats) is due to the fact that: 'A certain minimum time is needed for a heart to contract, expel blood, relax and be filled again, ready for the next contraction' [31]. The deviation in large

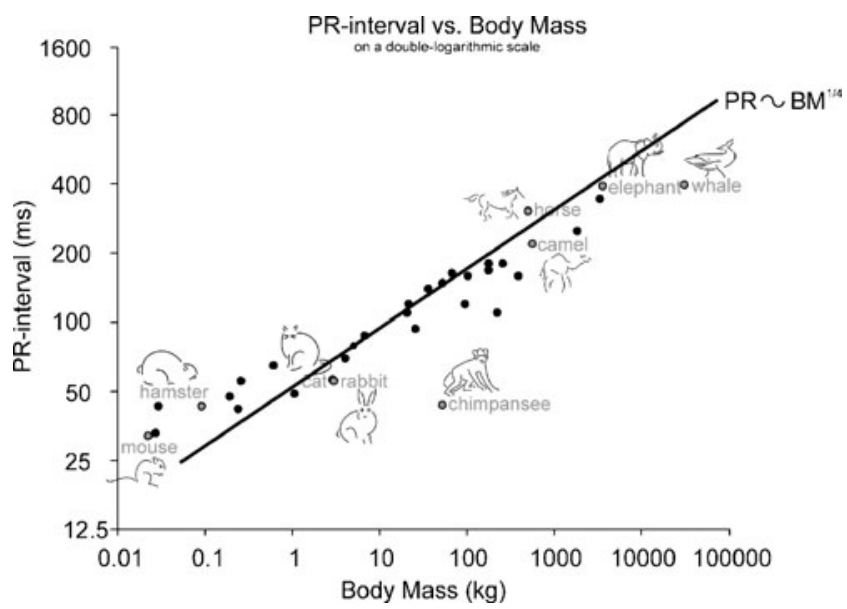

Fig. 2 Bosy mass versus PR interval in a number of mammals. The PR interval is proportional with the fourth root of body mass. See also Noujaim et al [37]. For further details see text. Design by Dr F.W. Lindemans, artwork by Jan de Jonge, Maastricht, the Netherlands mammals (larger than horses) is at least partly due to slower than expected heart rates. These lower heart rates are caused by a diminishing specific metabolic rate (metabolic rate per $\mathrm{kg}$ body mass, MBR), with body mass which decreases with increasing body size; the regression line having a slope of $-0.25[31], M B R=\mathrm{MBR}_{0} \mathrm{M}^{-0}$ [25]. It turns out that the fourth root line shows an almost perfect fit as already described by Noujaim et al. in 2004 [37]. Figure 3 shows the large difference in conduction velocity in the hearts of a mouse and a whale, almost by a factor 100. The contribution of the AVN to the total AV delay is large (even almost total) in small mammals and relatively limited, though as vital, in large mammals [38]. This scaling of conduction velocities is caused by size dependent conduction properties of the AVN. In all mammalian hearts scaling of $\mathrm{AV}$ conduction time follows the universal law for simple allometric scaling to ensure an optimal atrioventricular activation sequence' [37]. The mechanism responsible for this scaling, the morphological and molecular substrate, respectively, is unknown.

Scaling of the PR interval occurs in mammals of different species but also in differently sized mammals of one and the same species [39], small versus large (dogs, chimpanzees, horses) and in humans (babies, children, adults) [39-41]. Whether or not scaling is a product of
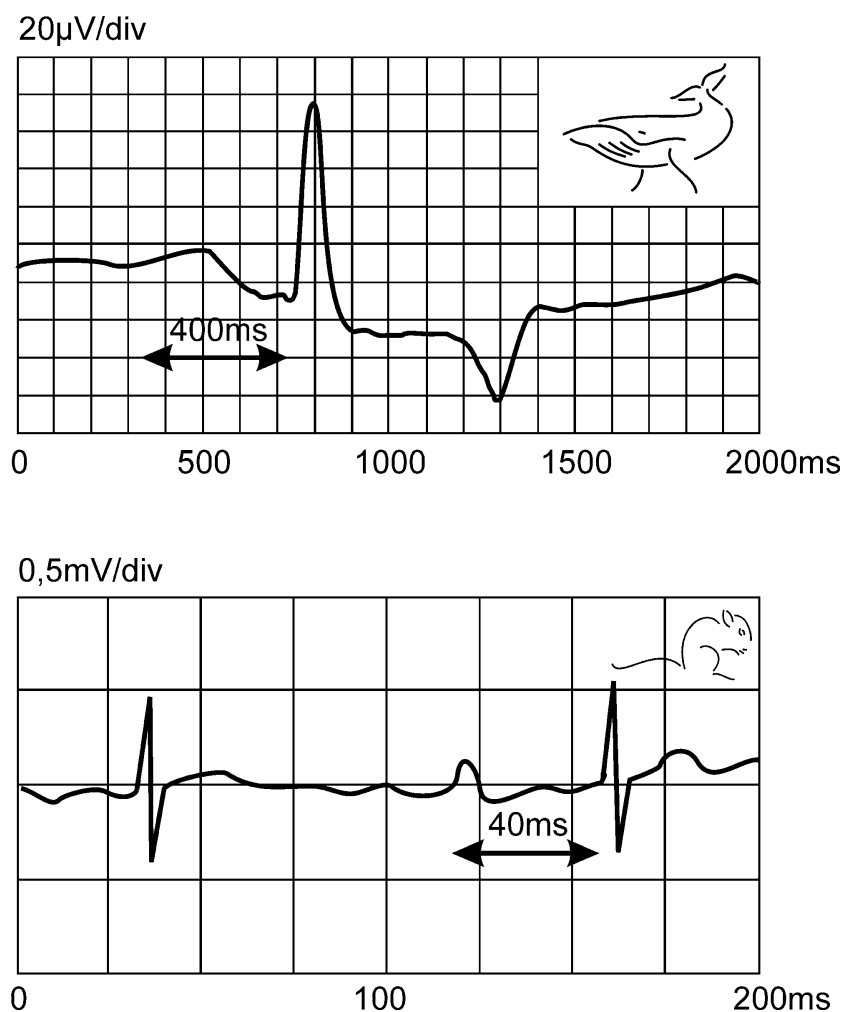

Fig. 3 Artist's presentation of AV conduction velocity in a mouse and a whale. This figure demonstrates that the PR interval in the whale is only $10 \times$ as long as in the mouse and thus $\mathrm{AV}$ conduction velocity is $100 \times$ higher. Artwork Jan de Jonge 
natural selection is a debatable issue with no simple answer. We question if scaling of the PR interval relation to heart mass or body mass in different mammalian species is an expression of evolutionary adaptation. Perhaps it is simply (?) a matter of adjustment to size without adaptation by natural selection. We tend to conclude that differences in $\mathrm{AV}$ conduction time between mammals have not been caused by the genetic differences between species but that they follow the universal law for allometric scaling.

The Haemodynamic Function of the Mammalian Heart

The mammalian heart is a suction-pressure pump made of muscle. Heart mass and stroke volume have a scaling factor of 1 . Haemodynamic parameters of the heart with respect to pressures in heart chambers and arteries (blood pressure) are, as far as it has been studied, of the same order of magnitude in all mammalian species. Since maintaining laminar flow depends on the pressure differences between two sites of a conduit, A and B, the flow velocity of arterial blood is, in comparable blood vessels (e.g., aorta, capillaries), also similar in all mammals. The adjustment (scaling) of AV conduction velocity compensates for size differences, resulting in the strong similarity and optimal haemodynamic function of the heart.

\section{An Analogy}

In information technology (IT), the presence of an infrastructure, a combination of basic physical and organisational structures, is required for the operation of a system. It ensures the interaction and collaboration between the components of such a system, so that it can fulfil its function. An infrastructure, as for example an 'enterprise service bus' (ESB) in computer science, is quite unspecific, (and thus general) and stable, when compared with the precise components that it has to support. Such an infrastructure can support a wide variety of systems with different ranges of functionalities as shown in Fig. 4.

One could hypothesise that the versatility of the mammalian heart fits this same principle. The heart is indeed a kind of ESB, an infrastructural element supporting a variety of animal body parts with different ranges of functionalities. The heart ejects blood that is unspecific for the precise bodily parts that it serves. Why would the concept of the generality of an infrastructure found in computer sciences also be valid for a heart, which is a product of nature? The answer could be that the external world poses direct requirements on the body as a whole with all its bodily parts, such as extremities, eyes, brains etc., while the requirements posed on the heart are (only) indirectly based on the external world, namely they are based on the sum of the needs of those bodily parts. The heart is not involved in the distribution of the blood it ejects. We feel that this analogy with IT makes the uniformity in the form and function of the heart in all mammals better understandable.

\section{General Considerations}

Houses, skyscrapers and other constructions of different sizes are hardly ever built in the same way. There are numerous designs and different materials used for all kind of structures around us. For example the Brooklyn Bridge in New York was built using different material from the wooden bridges in Amsterdam. In living nature, however, design and material often remain the same in organs with the same function irrespective of widely differing sizes. Homologous organs exhibit a homologous anatomy. However, after 65 million years of natural selection the differences between homologous organs can be considerable, although some organs, for instance the eyes in different mammalian species, exhibit a certain degree of conservation.

Changes in body shape and size of mammals during evolution called for scaling of organs and their functions. However, in spite of strong adaptation and vast diversification of mammals during evolution, the hearts and other organs of all mammals have originated from one and the same blueprint [42]. During descent mammalian hearts kept their original form, they look alike and indeed are (almost) alike. This does not prove that there has been no modification of the mammalian heart at all, but its undeniable conservation shows a striking contrast with the evolutionary diversification of the rest of the mammalian body.

A change in form is needed for a change in function [43]. Micro- and macro-morphology is similar in all mammalian hearts, thus has hardly been modified throughout 'descent with modification'. It follows, also from this point of view, that the electricity and haemodynamics of the heart had to remain similar as well. Scaling of the AV/PR delay/interval has been an enigma for a long time. We finally realised that simple allometric scaling can satisfactorily explain the mismatch and solves the riddle that we earlier perceived [9, 37]. However, the physiology (cellular or molecular substrate) of the scaling mechanism, resulting in large differences of $\mathrm{AV}$ conduction velocity, is to the best of our knowledge unknown and therefore deserves further study.

Erasmus Darwin, the grandfather of Charles Darwin, had already noticed this stability of supportive functions in living nature. He called this 'Pervasive Utility': 'New structures arose (it is now safe to say: arise) only when 


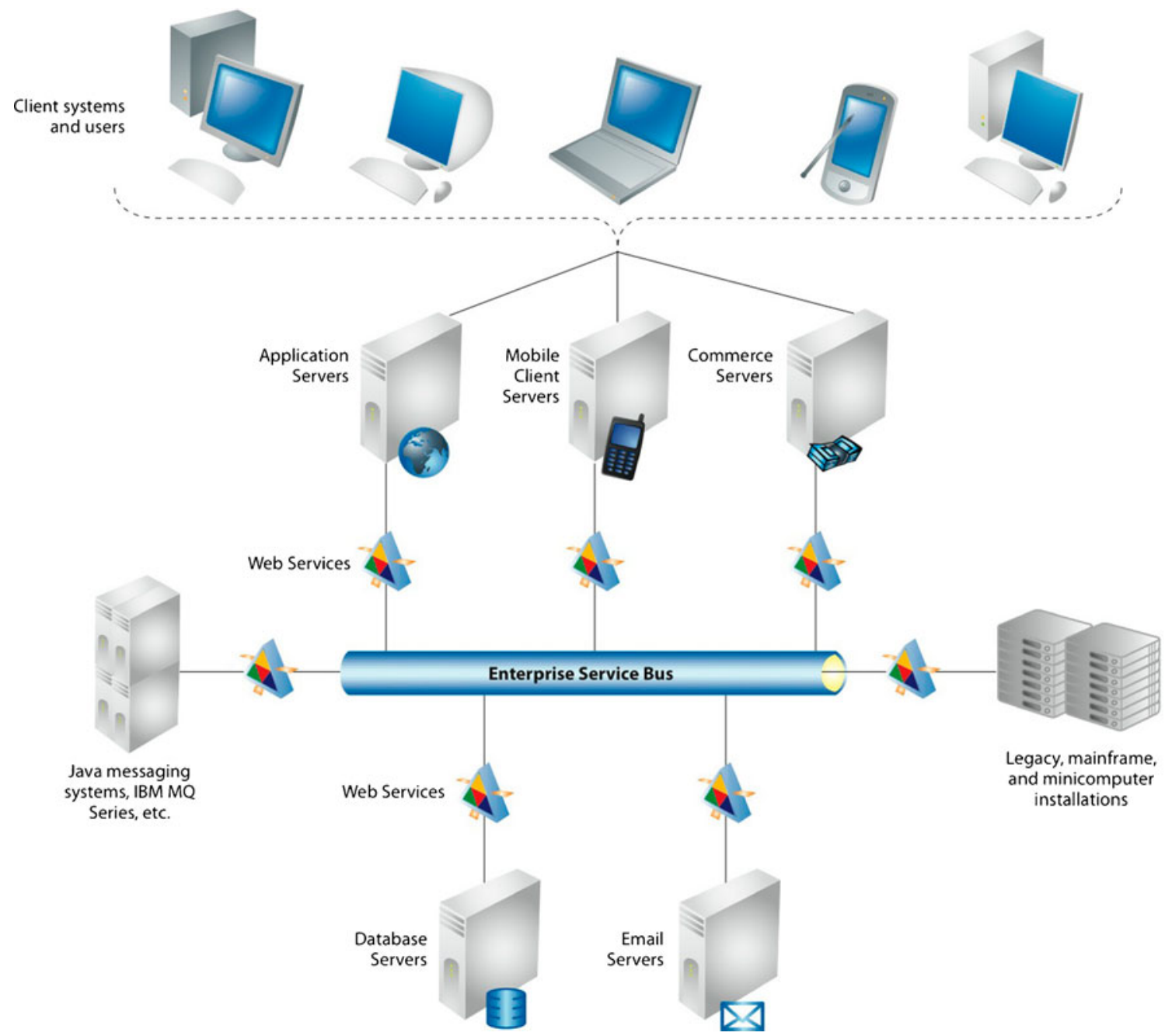

Fig. 4 Schematic representation of a so-called 'enterprise service bus' (ESB). An ESB can be viewed as the 'heart' of a complex computer system. Its relative immutability resembles the immutability of the heart

in an mammalian body. Reproduced from: (http://msdn.microsoft.com/ en-us/library/cc487894.aspx)

needed and by direct organic striving for an evident purpose' [43].

Still, the question remains as to what causes the heart to scale so well? It simply had to because otherwise the diversity of each differently sized or shaped mammalian species would have required a different heart, like different engines in differently sized vehicles such as mopeds, cars, trucks, trains or planes. The scaling of the heart with its functions can be observed during growth of one single mammal as well as between all species of the mammalian class [40, 41]. This makes the heart a unique organ and in this uniqueness it is not challenged by any other vital organ.

\section{Conclusion}

The very first representatives of the currently living mammalian orders made their entry on earth at the end of

Cretaceous. During Darwin's descent with modification [3] many and diversified mammalian species developed. From 'then' until 'now' the differences in size and shape of mammalian species became spectacular. What happened to their hearts? Next to nothing.

We conclude that the present mammalian heart is similar to that of their last common ancestor that appeared on earth, 125 million years ago. ${ }^{2}$ In other words the heart was hardly if at all affected by the evolutionary adaptations that shaped all mammalian species.

An important result of this study is the question as to what substrate is responsible for scaling of the $\mathrm{AV}$ conduction time in all mammals. Whether or not scaling in general is a product

\footnotetext{
${ }^{2}$ Given the uncertainty of the beginning of present mammalian evolution, a clear definition of 'the very first placental mammal' as we know it today is not really available. Evidence from molecules suggests that this common ancestor lived more than 100 million years ago
} 
of natural selection is a debatable issue with no simple answer. However, the answer to the question as to what causes scaling of $\mathrm{AV}$ conduction time could be of importance for better understanding the effect of atrial fibrillation in humans on the rate and rhythm of the ventricles.

Acknowledgements This paper could not have been materialised without the help and support of quite a few friends and peers. We would have preferred to give of each one her or his qualifications, because a combination of knowledge of cardiac morphology and function together with expertise in evolution biology and mathematics is hard to come by. We list the names of the colleagues who helped us in alphabetical order: Dr. Jacques de Bakker (Amsterdam, NL), Dr. Rona Mackie Black (Glasgow, UK), Dr. Henry Blackburn (Minneapolis, MN, USA), Dr. Leonard Dreifus (Heathrow, Fl, USA), Dr. José Jalife (Ann Arbor, MI, USA), Dr. Wilfried de Jong (Nijmegen, NL), Dr. Fred Lindemans (Maastricht, NL), Dr. David Reznick (Riverside, CA, USA), Dr. Jutta Schaper (Bad Nauheim, Germany), Dr. Hein Wellens (Maastricht, NL), Dr. Nico Westerhof (Amsterdam, NL).

Open Access This article is distributed under the terms of the Creative Commons Attribution Noncommercial License which permits any noncommercial use, distribution, and reproduction in any medium, provided the original author(s) and source are credited.

\section{References}

1. Bootsma BK, Hoelen AJ, Strackee J, et al. Analysis of R-R intervals in patients with atrial fibrillation at rest and during exercise. Circulation. 1970;41:783-94.

2. Van Gelder IC, Groeneveld HF, Crijns HJGM, et al. Lenient versus strict rate control in patients with atrial fibrillation. N Engl J Med. 2010;362:1363-73.

3. Billette J, Tadros R. Imminent ganglionic ventricular rate control during atrial fibrillation. J Cardiovasc Electrophysiol. 2010;21:200-2.

4. Meijler FL. Atrial fibrillation: A new look at an old arrhythmia. J Am Coll Cardiol. 1983;2:391-3.

5. Moe GK. On the multiple wavelet hypothesis of atrial fibrillation. Arch Int Pharmacodyn. 1962;140:183-8.

6. Moe GK, Rheinboldt WC, Abildskov JA. A computer model of atrial fibrillation. Am Heart J. 1964;67:200-20.

7. Meijler FL. Atrioventricular conduction versus heart size from mouse to whale. J Am Coll Cardiol. 1985;5:363-5.

8. Meijler FL, Janse MJ. Morphology and electrophysiology of the mammalian atrioventricular node. Physiol Rev. 1988;68:608-47.

9. Meijler FL. The mismatch between size and function of the heart. Proc R Neth Acad Sci. 1990;93:463-7.

10. Gould SJ. Archetype and adaptation. Nat Hist. 1986;95/10:6-27.

11. Weil A. Mammalian Evolution; Upwards and onwards. Nature. 2002;416:798-9.

12. Luo Z-X. Transformation and diversification in early mammal evolution. Nature. 2007;450:1011-9.

13. Pagel M. Natural selection 150 years on. Nature. 2009;457:808-9.

14. Reznick DN. The Origin Then and Now; An Interpretive Guide to the Origin of Species. Princeton and Oxford: Princeton University Press; 2010. p. 37.

15. Clegg PC, Clegg AG. Biology of the Mammal. London: Heinemann; 1975. p. 227.

16. Barth E, Stämmler G, Speiser B, et al. Ultrastructural quantification of mitochondria and myofilaments in cardiac muscle from 10 different species including man. J Moll Cell Cardiol. 1992;24:669-81.

17. Sommer JR, Johnson EA. Comparative ultrastructure of cardiac cell membrane specializations. A review. Am J Cardiol. 1970;25:184-94.
18. Sommer JR, Johnson EA. Ultrastructure of cardiac muscle. In: Berne RM, Sperelakis N, Geiger SR, editors. Handbook of Physiology. The Cardiovascular System. I. The heart. Bethesda: American Physiological Society; 1979. p. 113-86.

19. Schaper J, Stämmler G. Comparative morphometry of mammalian myocardium. Proc R Neth Acad Sci. 1990;93:501-5.

20. Truex RC, Smythe MQ. Comparative morphology of the cardiac conduction tissue in mammals. Ann NY Acad Sci. 1965;127:19-33.

21. Meyling HA, ter Borg H. The conduction system of the heart in hoofed animals. Cornell Vet. 1957;47:419-55.

22. Slijper EJ. Walvissen. Amsterdam: DB Centen's Uitgeversmaatschappij; 1958. p. 190-1.

23. James TN. Structure and function of the AV junction. Jpn Circ J. 1983;47:1-47.

24. Rowlatt U. Comparative anatomy of the heart of mammals. Zool J Linn Soc. 1990;98:73-110.

25. Candinas D, Adams DH. Xenotransplantation: postponed by a millennium? Editorial. QJM. 2000;93:63-6.

26. Crick SJ, Sheppard MN, Ho SY, et al. Anatomy of the pig heart: comparisons with normal human cardiac structure. J Anat. 1998;193:105-19.

27. Alpert NR, Brosseau C, Federico A, et al. Molecular mechanics of mouse cardiac myosin isoforms. Am J Physiol Heart Circ Physiol. 2002;283:H1446-54.

28. Durrer D, van Dam RTh, Freud GE et al. Total excitation of the isolated human heart. Circulation. 1970;41:895-912.

29. Durrer D, Janse MJ, Lie KI, et al. Human cardiac electrophysiology. In: Dickinson CJ, Marks J, editors. Developments in Cardiovascular Medicine. Lancaster: MTP Press; 1975. p. 53-75.

30. Galileo Galilei, translated by Henry Crew and Alfonso de Salvio. Dialogues Concerning Two New Sciences. McGraw-Hill Paperbacks: Northwestern University Press; (1963), p. 126.

31. Schmidt Nielsen, K. Scaling Why is Animal Size so important? Cambridge UK: Cambridge University Press; 1984, pp. 143-5.

32. Prothero J. Heart weight as a function of body weight in mammals. Growth. 1979;43:139-50.

33. Teissier G. Biometrie de la cellule. Tabulae Biol. 1939;19:1-64.

34. Clark AJ. Comparative Physiology of the Heart. Cambridge: Cambridge University Press; 1927. p. 49-51.

35. Meijler FL, Van der Tweel LH. De elektrocardiogrammen van 10 olifanten en van de orka in Harderwijk. Ned Tijdschr Geneeskd. 1986;130:2344-8.

36. Meijler FL, Wittkampf FHM, Brennen KR, et al. Electrocardiogram of the Humpback Whale (Megaptera Novaengliae), with specific reference to atrioventricular transmission and ventricular excitation. J Am Coll Cardiol. 1992;20:475-9.

37. Noujaim SF, Lucca E, Munoz V, et al. From mouse to whale: The PR interval follows the universal allometric scaling law of biology. Circulation. 2004;110:2802-8.

38. Meijler FL, Billette J, Jalife J, et al. Atrioventricular conduction in mammalian species: Hemodynamic and electrical scaling. Heart Rhythm. 2005;2:188-96.

39. Wassenaar C. Comparative electrocardiography in mammals [thesis]. Utrecht: University of Utrecht; 1993.

40. Van Wezel-Meijler G, van Genderen HR, Meijler FL. Atrioventriculaire geleidingstijd bij te vroeg geborenen ongeveer de helft van die bij volwassenen. Ned Tijdschr Geneeskd. 1997;141:244-7.

41. Van der Tweel LH, Strackee J, Stokhof AA, et al. ECG of the 'Newborn' mouse (Mus Domesticus) with specific reference to comparative AV transmission. J Cardiovasc Electrophyiol. 1999; 10:168-73.

42. James TN, Kawamura K, Meijler FL, et al. Anatomy of the sinus node, AV node and His bundle of the heart of the sperm whale (Physeter macrocephalus), with a note on the absence of an os cordis. Anat Rec. 1995;242:355-73.

43. Gould SJ. Freudian Slip. Nat Hist. 1987;96/2:14-22. 